\title{
Co-electrolysis toward value-added chemicals
}

\author{
Lisong Chen ${ }^{1^{*}}$ and Jianlin $\mathrm{Shi}^{\mathrm{i}^{*}}$
}

\begin{abstract}
Current major electrocatalytic reactions, such as hydrogen evolution reaction, carbon dioxide reduction reaction, and nitrogen reduction reaction, focus on single-target chemical production, which suffers from strong competitive reactions at the same electrodes and/or high energy barrier reactions at the counterpart electrodes. The co-electrolysis of more than one kind, typically two kinds, of chemical precursors in one electrolytic system is therefore a highly attractive strategy for both energy input reduction and concurrent production of double value-added chemicals. Exciting progress has been achieved in this area recently, and a timely review on this specific topic will be highly desired. In this review, the reported co-electrolysis systems are classified into four categories: (1) agent sacrificing at one electrode promoting electrochemical precursor conversion at the other; (2) parallel electrochemical precursor conversions, i.e., electrosyntheses, simultaneously at both sides; (3) electrochemical conversions of two precursors at both sides into one/the same product; (4) double/multiple electrochemical conversions at one side. The current challenges and future opportunities of co-electrolysis toward high value-added products are discussed at the end.
\end{abstract}

Keywords: co-electrolysis, value-added chemicals, electrocatalysts

\section{INTRODUCTION}

The contradiction between the limited reserves of fossil fuels and growing energy demand, as well as the increasing environmental pollution crisis, has greatly promoted the development of sustainable energy techniques and novel chemical production approaches. Electrolysis uses electricity generated from reproducible solar energy, wind energy, and hydraulic power to produce high value-added products, providing a highly promising technique for a sustainable society [1]. Nowadays, electrocatalytic water splitting for hydrogen evolution reaction (HER), electrocatalytic carbon dioxide reduction $\left(\mathrm{CO}_{2} \mathrm{R}\right)$ for carbon dioxide capture and production of carbon-based fuels, electrocatalytic nitrogen reduction (NRR) into ammonia, and many other electrochemical reactions have become hot topics on the frontiers of science and technology [2-4]. Significant efforts have been made, and great progress has been achieved in catalyst design and electrolyzer configuration optimization. Most attention has been focused on obtaining a single-target chemical up to date. However, serious side but competitive reactions must be suppressed, and the high energy barrier of counterpart reactions must be lowered to industrialize such an advanced route for chemical production. For example, HER by electrocatalytic water splitting is highly desirable but suffers from slow kinetic anodic oxygen evolution reaction (OER) at the counter electrode. In addition, both nitrogen and $\mathrm{CO}_{2}$ reductions are highly desired for ammonia and fuel productions, respectively, but their Faraday efficiencies are reduced by the competitive HER at the same electrode due to the comparable potentials needed [5]. To obtain target chemicals more efficiently, novel electrolytic configurations and highly active and specific electrocatalysts are urgently needed to promote the target reaction while suppressing competitive reactions at the same or counter electrode.

In the past few years, a co-electrolysis strategy has been advocated to solve the above problems. The main goal of this coelectrolysis strategy is to electrolyze more than one kind of chemical precursors at the same time for the production of high value-added products at a lower energy input. Thermodynamically and kinetically favorable reactions will occur much more easily, i.e., at much higher rates, than the less thermodynamically and kinetically favorable reactions once two or multiple precursors are added to one cell, therefore resulting in lowered energy consumption. For example, the kinetically slow OER can be alternated by a reductive chemical oxidation reaction of small organic molecules for the efficient synthesis of hydrogen by water splitting, namely, chemical-assisted hydrogen evolution [6]. More importantly, products with higher value could be obtained from the kinetically favorable reactions. For example, value-added formate could be synthesized when OER is replaced by glycol oxidation [7]. Although exciting progress has been achieved in this area, no specific review has been conducted on this topic $[1,2,4,6,8,9]$. A specific tutorial review is of significance for the fast development of a co-electrolysis system.

To provide a clear picture on the co-electrolysis toward valueadded products, the currently reported co-electrolysis systems are classified into four categories (Scheme 1) in this review: (1) agent sacrificing at one electrode and promoting precursor electrochemical conversion at the other; (2) parallel electrochemical precursor conversions, i.e., electrosyntheses, simultaneously at both sides; (3) electrochemical conversions of two

\footnotetext{
${ }^{1}$ Shanghai Key Laboratory of Green Chemistry and Chemical Processes, School of Chemistry and Molecular Engineering, East China Normal University, Shanghai 200062, China

${ }^{2}$ State Key Laboratory of High Performance Ceramics and Superfine Microstructures, Shanghai Institute of Ceramics, Chinese Academy of Sciences, Shanghai 200050, China

* Corresponding authors (emails: 1schen@chem.ecnu.edu.cn (Chen L); jlshi@mail.sic.ac.cn (Shi J))
} 

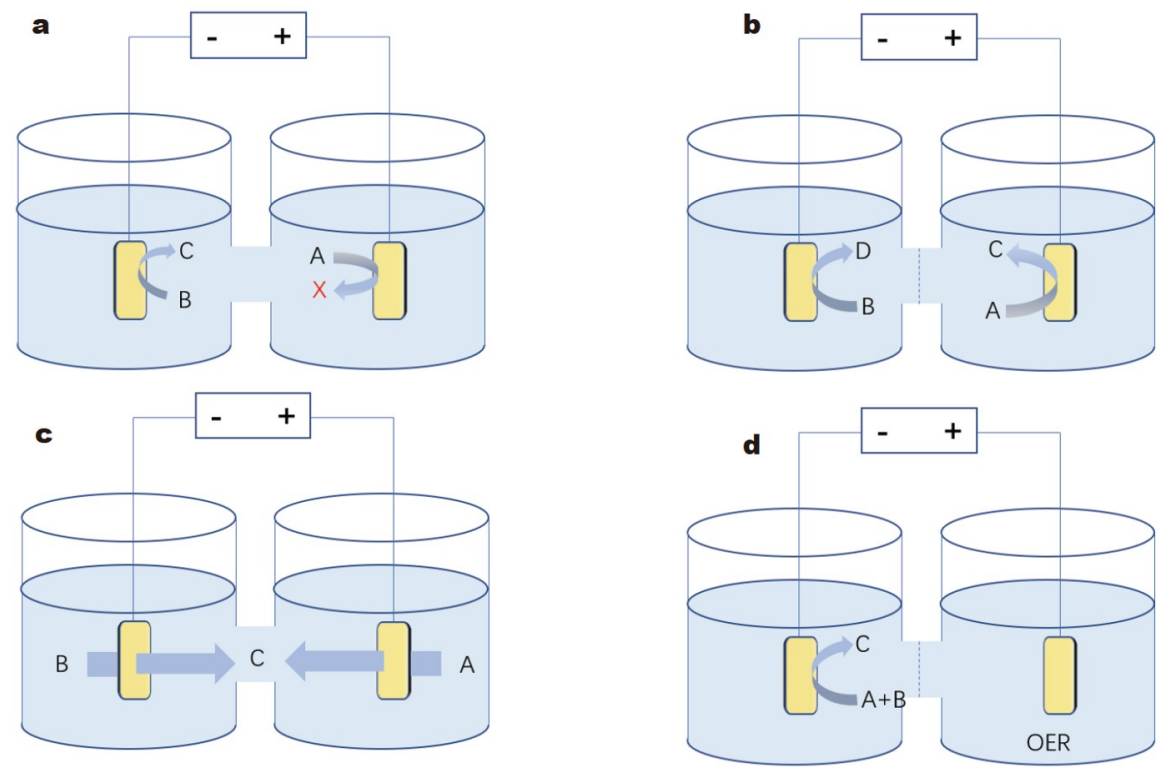

Scheme 1 Illustrations of typical co-electrolysis systems. (a) Agent (A) sacrificing at one electrode to promote the conversion of target precursor (B) to product $(C)$ at the other; (b) parallel electrochemical precursor (A and B) conversions, i.e., electrosyntheses, into products (C and D) simultaneously at both sides; (c) electrochemical conversions of two precursors (A and B) at both sides into one/the same product (C); (d) double/multiple electrochemical conversions of precursors (A and $B$ ) into product $(C)$ at one side.

precursors at both sides into one/the same product; and (4) double/multiple electrochemical conversions at one side. This review is expected to be able to shed light on the research area of co-electrolysis and benefit the production of high value-added chemicals at reduced energy consumption.

\section{AGENT SACRIFICING AT ONE ELECTRODE PROMOTING ELECTROCHEMICAL PRECURSOR CONVERSION AT THE OTHER}

Electrocatalytic oxygen evolution is one of the most important half-reactions in electrolysis, which is a counterpart of the cathode side of the most popular HER, $\mathrm{CO}_{2} \mathrm{R}, \mathrm{NRR}$, and organic redox reactions. However, its sluggish kinetics has greatly hampered the large-scale applications of these reactions for the production of high-purity hydrogen, carbon-based chemicals, and ammonia. Moreover, the produced oxygen is of less value because it can be easily obtained from the atmosphere. More seriously, reactive oxygen species might be generated during the electrolysis in the presence of oxygen, which would degrade the membrane and shorten the lifetime of the electrolyzer. Recently, sacrificial agents, such as hydrazine and urea, have been added to these electrolysis systems to replace the OER through the sacrificial agent oxidation reactions (Fig. 1a). As a typical example, Tang et al. [10] introduced a kinetically favorable hydrazine oxidation reaction $\left(\mathrm{HzOR}: \mathrm{N}_{2} \mathrm{H}_{4}+4 \mathrm{OH}^{-} \rightarrow \mathrm{N}_{2}+\right.$ $\left.4 \mathrm{H}_{2} \mathrm{O}+4 \mathrm{e}^{-}\right)$to substitute for anodic OER in electrocatalytic water splitting in basic media (Fig. $1 \mathrm{~b}, \mathrm{c}$ ). The obtained $\mathrm{Ni}_{2} \mathrm{P} / \mathrm{NF}$ $\left(\mathrm{Ni}_{2} \mathrm{P}\right.$ nanoarrays grown on nickel foam) served as a bifunctional efficient electrocatalyst both for HzOR and HER. Therefore, when $\mathrm{Ni}_{2} \mathrm{P} / \mathrm{NF}$ was equipped as both the anode and cathode, the two-electrode electrolyzer achieved a current density of as high as $500 \mathrm{~mA} \mathrm{~cm}^{-2}$ at a cell voltage as low as $1 \mathrm{~V}$ with long-time stability and a high Faraday efficiency of $100 \%$ for HER. Since then, various sacrificial agents, such as ammonia and urea, have been adopted, and different electrocatalysts, such as transition metal oxide, sulfide, and phosphide, have been developed. Zhang et al. [12] synthesized tubular $\mathrm{CoSe}_{2}$ nanosheet electrocatalysts, which achieved a current density of $10 \mathrm{~mA} \mathrm{~cm}^{-2}$ at a potential as low as $-84 \mathrm{mV}$ for HER and $-17 \mathrm{mV}$ for $\mathrm{HzOR}$. When $\mathrm{CoSe}_{2}$ was used as the anode and cathode in a $1 \mathrm{~mol} \mathrm{~L}^{-1} \mathrm{KOH}$ electrolyte solution containing $0.5 \mathrm{~mol} \mathrm{~L}^{-1}$ hydrazine, such an electrolyzer system needed an ultralow cell voltage of $0.164 \mathrm{~V}$ to achieve the current density of $10 \mathrm{~mA} \mathrm{~cm}^{-2}$. Recently, Li et al. [11] reported the scalable synthesis of carbon porous microsheets decorated by partially exposed $\mathrm{RuP}_{2}$ (denoted as RPCPM, Fig. 1d-f). Once used as a bifunctional electrocatalyst, ultralow potentials of -70 and $24 \mathrm{mV}$ were necessary to achieve $10 \mathrm{~mA} \mathrm{~cm}^{-2}$ for $\mathrm{HzOR}$ and HER, respectively. The two-electrode electrolytic cell could be operated at a cell voltage of $23 \mathrm{mV}$ for $10 \mathrm{~mA} \mathrm{~cm}^{-2}$ by using the obtained materials as both anodic and cathodic electrocatalysts, which is the lowest voltage as far as we know. Moreover, a current density of as high as $522 \mathrm{~mA} \mathrm{~cm}^{-2}$ was reached at $1.0 \mathrm{~V}$. Sun et al. [13] reported the co-electrolysis of sea water with hydrazine, which obtained a fast hydrogen evolution rate of $9.2 \mathrm{~mol} \mathrm{~h}^{-1} \mathrm{~g}_{\mathrm{cat}}{ }^{-1}$ and a much lowered electricity expense of $2.75 \mathrm{kWh}$ per cubic meter of $\mathrm{H}_{2}$ at the current density of $500 \mathrm{~mA} \mathrm{~cm}^{-2}$ catalyzed by the NiCo/MXene electrocatalyst. The chlorine electrochemistry can also be avoided due to the lowered cell voltages.

In addition to the electrocatalytic water splitting for HER, OER is a counterpart reaction of $\mathrm{CO}_{2} \mathrm{RR}$ for high-value carbonbased fuels and NRR for ammonia synthesis. The co-electrolysis of sacrificial agents in $\mathrm{CO}_{2} \mathrm{RR}$ and NRR is also critical for efficient electrocatalytic $\mathrm{CO}_{2}$ reduction and NRR. Verma et al. [5] reported the co-electrolysis of glycerol and $\mathrm{CO}_{2}$ to reduce the total energy input. Up to $53 \%$ electricity consumption can be saved when compared with conventional $\mathrm{CO}_{2}$ reduction, because OER is replaced by thermodynamically favorable glycerol oxidation processes. They also predicted that with the development of more active electrocatalysts, the co-electrolysis efficiencies of 

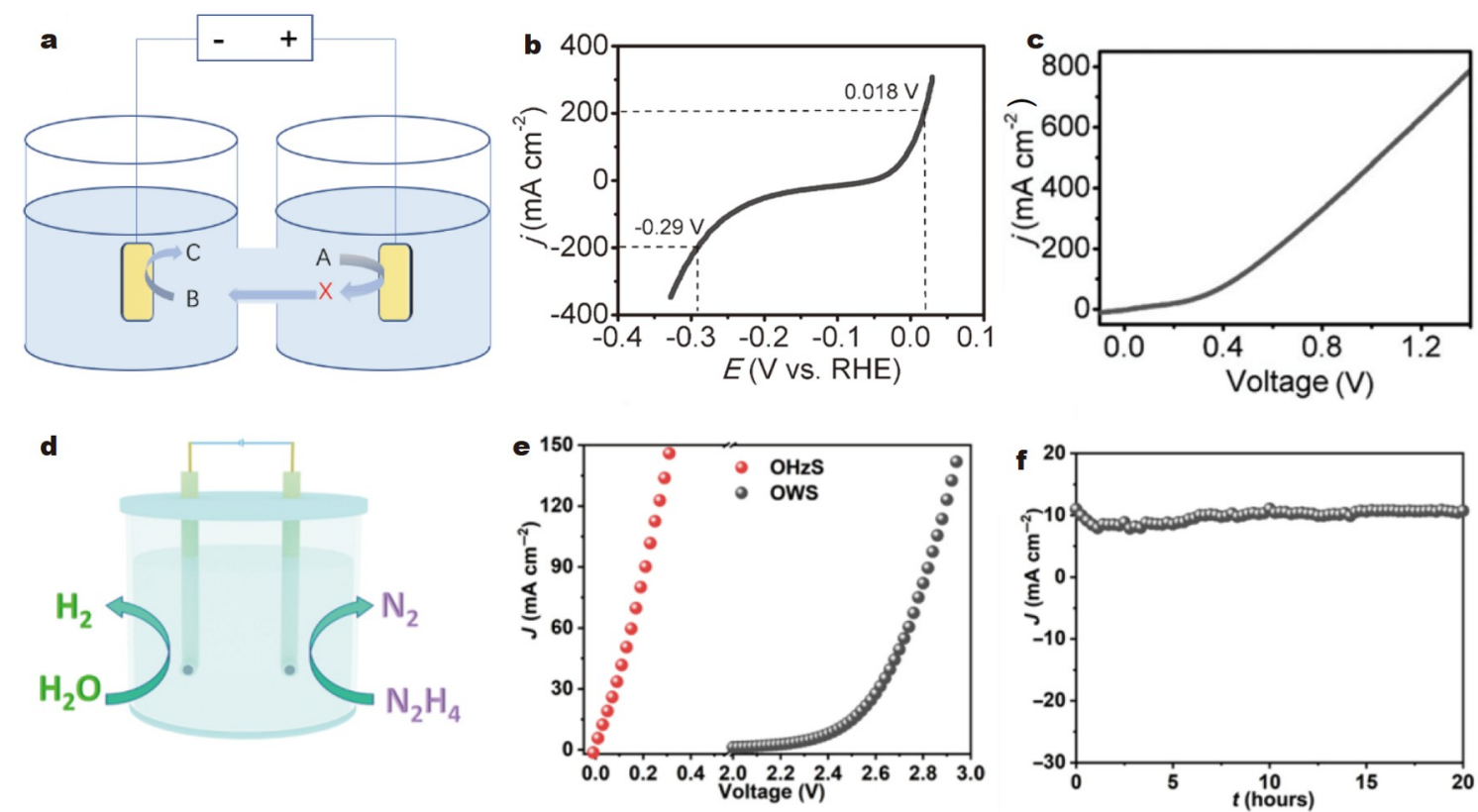

Figure 1 (a) Illustration of agent sacrificing at one electrode promoting the electrochemical precursor conversion at the other; (b) HER and HzOR performance of $\mathrm{Ni}_{2} \mathrm{P} / \mathrm{NF}$; (c) co-electrolysis performance of $\mathrm{Ni}_{2} \mathrm{P} / \mathrm{NF}$ in a two-electrode electrolyzer. Reproduced from Ref. [10] with permission, Copyright 2017, Wiley-VCH Verlag GmbH \& Co. KGaA. (d) Schematic illustration of the co-electrolysis of $\mathrm{H}_{2} \mathrm{O}$ and $\mathrm{N}_{2} \mathrm{H}_{4}$; (e) LSV curve and (f) stability of RP-CPM for the co-electrolysis of $\mathrm{H}_{2} \mathrm{O}$ and $\mathrm{N}_{2} \mathrm{H}_{4}$. Reproduced from Ref. [11] with permission, Copyright 2020, The Authors, exclusive licensee American Association for the Advancement of Science.

both glycerol and $\mathrm{CO}_{2}$ could be further improved for energyefficient utilization of waste $\mathrm{CO}_{2}$. However, no anodic reaction products have been obtained or reported. Therefore, glycerol served only as a sacrifice agent at the anode to accelerate the cathode hydrogen production.

\section{PARALLEL CHEMICAL PRECURSOR CONVERSIONS SIMULTANEOUSLY AT BOTH SIDES}

The agent sacrificing at one electrode promoting the electrochemical precursor conversion at the other strategy can significantly decrease the overall potential to drive the desired electrochemical reactions and obtain target products such as hydrogen at a lowered cost. However, the sacrifice agent adds to the cost, but no valuable products have been obtained. For example, the produced nitrogen and water are highly abundant in the environment, and the carbon dioxide from the oxidation of expensive hydrazine or urea is a greenhouse gas waste. Therefore, this strategy shows significantly lowered energy consumption in electrochemical reactions at the high cost of sacrifice agent losses. A more desirable approach is to convert the added sacrificing agent to value-added products during the electrode redox reaction (Fig. 2a).

To this end, a bifunctional Ni-Mo-N/CFC (nickel-molybdenum-nitride grown on carbon fiber cloth) electrocatalyst was developed by our group, which is electrochemically efficient for both HER at the cathode and glycerol oxidation at the anode in alkaline solutions [14] (Fig. 2b, c). The obtained Ni-Mo-N/CFC requires a potential of 40 or $43 \mathrm{mV}$ to reach the current density of $10 \mathrm{~mA} \mathrm{~cm}^{-2}$ in $0.1 \mathrm{~mol} \mathrm{~L}^{-1} \mathrm{KOH}$ without or with glycerol addition for HER, respectively. In addition, the obtained $\mathrm{Ni}-\mathrm{Mo}-$ N/CFC shows high activity for glycerol oxidation, and the oxidation potential to reach $10 \mathrm{~mA} \mathrm{~cm}^{-2}$ is decreased to $1.30 \mathrm{~V} v s$.
RHE. The anodic potentials to obtain the current densities of 10 , $20,50,100$, and $150 \mathrm{~mA} \mathrm{~cm}^{-2}$ are all reduced by more than $250 \mathrm{mV}$. Importantly, glycerol is converted to value-added formate with especially high selectivity. When Ni-Mo-N/CFC is used as a cathodic electrocatalyst for hydrogen evolution, only a small amount of Mo is dissolved in the electrolyte. When it serves as an anodic glycerol oxidation electrocatalyst, more than $90 \%$ of Mo dissolves in the electrolyte in a short time, and residual Mo species in the materials are completely oxidized to higher-valence $\mathrm{Mo}^{6+}$. These changes are helpful clues in investigating the real catalytic active sites. When Ni-Mo-N/CFC was used as both the anode and cathode in an electrolyzer with $1 \mathrm{~mol} \mathrm{~L}^{-1} \mathrm{KOH}$ containing $0.1 \mathrm{~mol} \mathrm{~L}^{-1}$ glycerol as the electrolyte, a cell voltage as low as $1.36 \mathrm{~V}$ was needed, which is significantly lower than that of the two-electrode water splitting system catalyzed by the same catalysts at both sides. Moreover, nearly $100 \%$ and $95.0 \%$ Faraday efficiencies can be obtained at the cathode for HER and the anode for formate production. This strategy features much decreased potential/energy input needed and the potential explosion risk removal in the case of cathodic hydrogen and anodic oxygen mixing. More importantly, highvaluable products were synthesized from low-cost biomass derivates instead of less valuable oxygen production. Therefore, this strategy, which was called electrosynthesis-assisted HER in a former review [4], has been arousing broad interest among researchers in this area and developing rapidly. The co-electrolysis of water with various small-molecule organics, such as glucose [15], methanol [16], ethanol [17], and benzylamine [18], has been reported recently, with hydrogen and the corresponding oxidation products being obtained at current densities of as high as $400 \mathrm{~mA} \mathrm{~cm}^{-2}$ [19]. The $\mathrm{C}-\mathrm{C}$ bond retention or cleavage is critically important in the conversion of many organic molecules to obtain value-added chemicals. However, it 

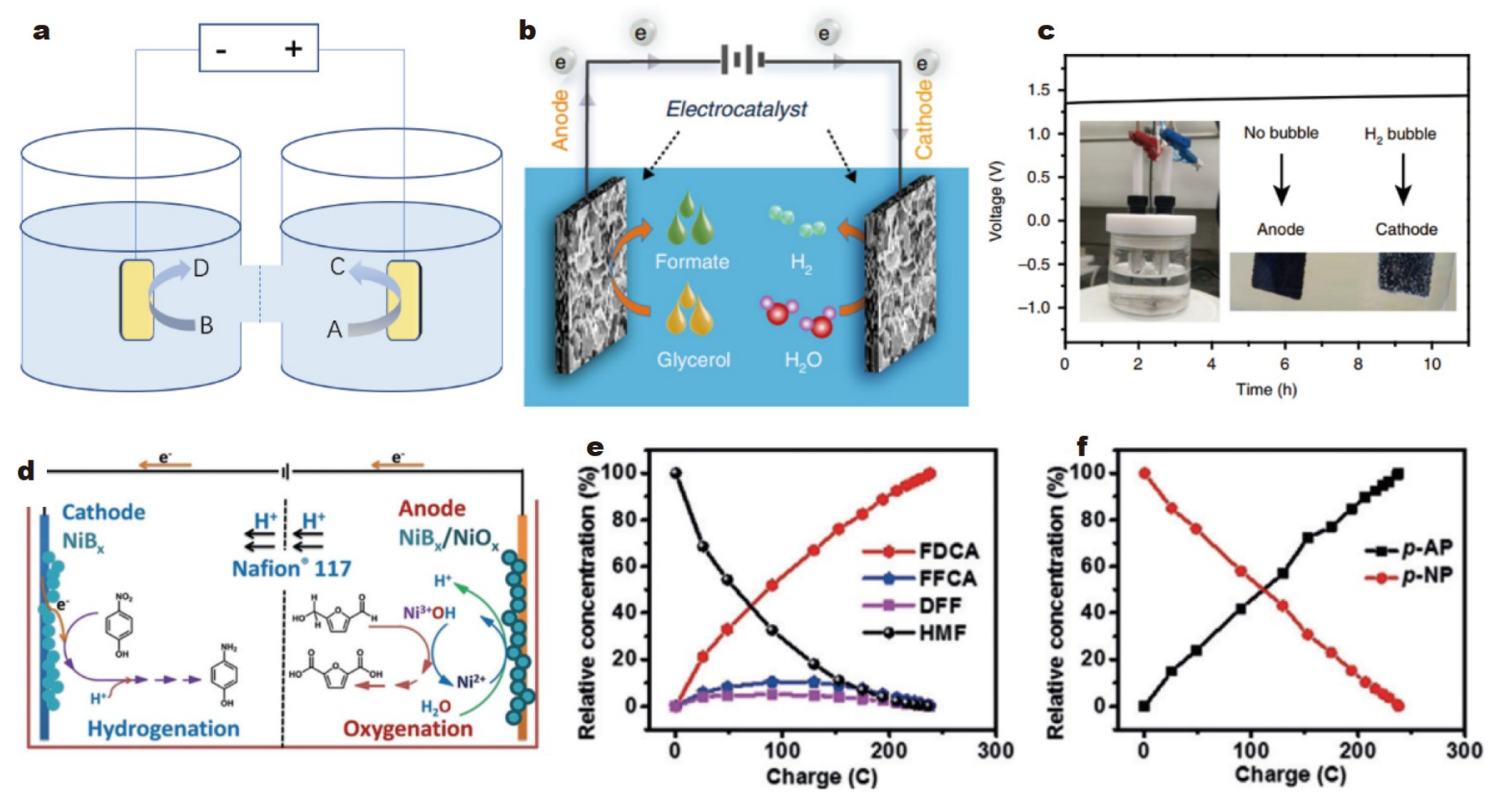

Figure 2 Schematic illustrations of (a) parallel electrochemical precursor conversions, i.e., electrosyntheses, simultaneously at both sides and (b) concurrent cathodic hydrogen evolution and anodic formate production from glycerol solution. (c) Stability performance of the Ni-Mo-N/CFC electrocatalyst. (b) and (c) are reprinted from Ref. [14]. (d) Schematic illustration of the co-electrolysis of two organics (5-hydroxymethylfurfural at the anode and $p$-nitrophenol at the cathode for the production of 2,5-furandicarboxylic acid and p-aminophenol, respectively). (e, f) Product analyses at the anode (e) and the cathode (f). Reprinted from Ref. [26] with permission, Copyright 2019, Wiley-VCH Verlag GmbH \& Co. KGaA.

is uncontrollable in most cases. Recently, the high efficiency and selectivity conversion of ethylene glycol to glycolic acid has been reported, catalyzed by a PdAg electrocatalyst grown on nickel foam [20]. When PdAg and Pt are equipped at the anode and cathode, respectively, glycolic acid and hydrogen can be obtained concurrently by the co-electrolysis of water and ethylene glycol at a much lowered potential.

This strategy was also used for the co-electrolysis of $\mathrm{CO}_{2}$ and organic chemicals for the syntheses of carbon-based fuels and value-added chemicals at the same time. Li et al. [21] reported the electrocatalytic $\mathrm{CO}_{2}$ reduction in tandem with organic substrate oxidations. At the cathode, $\mathrm{CO}_{2}$ is reduced to $\mathrm{CO}$ at a current density of $3.7 \mathrm{~mA} \mathrm{~cm}^{-2}$ and Faraday efficiency of higher than $70 \%$ under catalysis by copper-indium. At the anode, the oxidation of four typical alcohols, namely, 4-methoxybenzyl alcohol, 1-phenylethanol, ethanol, and isopropanol, which represent four different classes of alcohols, were used to replace OER, during which these alcohols were converted to their corresponding carbonyl compounds with yields higher than $75 \%$. Similarly, Wang et al. [22] and Bajada et al. [23] simultaneously obtained syngas and aldehyde through the co-electrolysis of $\mathrm{CO}_{2}$ and alcohol in aqueous solution with high efficiencies. The coelectrolysis strategy can also be used to lower energy consumption and obtain value-added chemicals for biomass upgrading. Zhou et al. [24] reported the co-electrolysis of ligninderived substrates and water, by which benzoate/adipate and hydrogen were obtained efficiently. Chong et al. [25] reported that the integration of hydrogen production/hydrogenation with Se promoted $\alpha$-nitrotoluenes electrooxidation, by which hydrogen/hydrogenation products and E-nitroethenes were obtained at a lowered potential.

The co-electrolysis of two organic chemicals in aqueous solutions has also attracted attention. Generally, organics are fed in the anode for oxidation and cathode for reduction to produce high value-added chemicals. Zhang et al. [26] prepared $\mathrm{NiB}_{x}$ as the bifunctional electrocatalyst at both the anode and the cathode for the paired oxygenation and hydrogenation of added organic chemicals, respectively, in which water in the electrolyte served as both hydrogen and oxygen sources. Simultaneous conversions of 5-hydroxymethyfurfural to 2,5-furandicarboxylic acid and $p$-nitrophenol to $p$-aminophenol were achieved with high efficiency and selectivity (Fig. 2d-f). The co-electrolysis of other kinds of organics was also demonstrated in this report.

This strategy was also used in photocatalysis to make the best use of photogenerated electrons and holes to obtain both reduction and oxidation products. For example, a NiS/CdS nanocomposite was synthesized and used as a bifunctional photocatalyst for benzyl alcohol oxidation and water splitting to obtain benzaldehyde and hydrogen, respectively [27]. The optimized NiS/CdS shows high hydrogen evolution and benzaldehyde generation rate as high as 207.8 and $163.8 \mu \mathrm{mol} \mathrm{h}^{-1}$, respectively, which are the highest rates for concurrent production of hydrogen and aldehyde ever reported in aqueous solution. Although a few reports have been conducted on photocatalytic parallel chemical precursor conversions [28-31], more attention should be paid to the development of more cophotocatalysis approaches.

\section{ELECTROCHEMICAL CONVERSIONS OF TWO PRECURSORS AT BOTH SIDES INTO ONE/THE SAME PRODUCT}

Although simultaneous chemical conversions at both sides of a co-electrolysis system can lower the energy input and produce value-added chemicals, the products are usually in rather low concentrations and unavoidably mix together in the electrolyte if the obtained products are both miscible in a liquid electrolyte, which leads to difficulties in the following separation and purification. If two precursors could be converted to the same 
product by simultaneous or successive electrode reactions, i.e., anodic oxidation reactions and the cathodic reduction reactions, then the above problem can be solved (Fig. 3a).

Most recently, the co-electrolysis of methanol and $\mathrm{CO}_{2}$ in one electrolysis system for synthesizing the same product was reported by our group [7]. $\mathrm{CO}_{2}$ is reduced at the cathode by a novel catalyst of mesoporous $\mathrm{SnO}_{2}$ grown on carbon cloth $\left(\mathrm{mSnO}_{2} / \mathrm{CC}\right)$, which exhibits a Faraday efficiency of as high as $81 \%$ at $0.7 \mathrm{~V} v s$. RHE for the conversion of $\mathrm{CO}_{2}$ to formic acid. At the anode, concurrently, the partial methanol oxidation catalyzed by $\mathrm{CuO}$ nanosheets grown on copper foam (CuONS/CF) was used to substitute for the kinetically slow OER process, which also generates formic acid with a high efficiency (100 mA cm ${ }^{-2} @ 1.47 \mathrm{~V}$ vs. RHE). Assembling $\mathrm{mSnO}_{2} / \mathrm{CC}$ and $\mathrm{CuONS} / \mathrm{CF}$ as the cathode and anode, respectively, together in one electrolyzer concurrently produces high value-added formic acid by the cathodic $\mathrm{CO}_{2}$ electroreduction and anodic methanol electrooxidation, and reasonably high Faraday efficiencies of $80.5 \%$ and $91.3 \%$ at the cathode and anode, respectively, were obtained. Moreover, a cell voltage of as low as $0.93 \mathrm{~V}$ is needed to reach $10 \mathrm{~mA} \mathrm{~cm}^{-2}$, which is much lower (by above $500 \mathrm{mV}$ ) than that of the $\mathrm{CO}_{2}$ electroreduction system without adding methanol at the anode. Such a simultaneous chemical conversion strategy will be an interesting approach for $\mathrm{CO}_{2}$ reduction with not only lowered energy input but also the same valueadded chemical productions at both sides (Fig. 3b, c), which is expected to be applicable to a number of other co-electrolysis systems.
The co-electrolysis of hydrogen and oxygen for the production of hydrogen peroxide is also a typical example in this regard. The anthraquinone process is still the main approach for hydrogen peroxide production, and it suffers from high energy costs, harmful organic by-products, and dangerous issues in the transportation and storage processes of high-concentration hydrogen peroxide. Although the direct synthesis of hydrogen peroxide from the mixture of hydrogen and oxygen has been explored for years, the flammability and potential explosion hazard of mixed high-pressure oxygen and hydrogen have prevented its large-scale industrialization. Recently, Xia et al. [32] demonstrated the direct electrosynthesis of hydrogen peroxide through the co-electrolysis of decoupled hydrogen and oxygen at the anode and cathode, respectively (Fig. 3d-f). The basic principles are shown in the following equations:

Anodic hydrogen oxidation reaction:

$\mathrm{H}_{2} \rightarrow 2 \mathrm{H}^{+}+2 \mathrm{e}^{-}$;

Cathodic $2 \mathrm{e}^{-}$oxygen reduction reaction:

$\mathrm{O}_{2}+\mathrm{H}_{2} \mathrm{O}+2 \mathrm{e}^{-} \rightarrow \mathrm{HO}_{2}{ }^{-}+\mathrm{OH}^{-}$;

Hydrogen peroxide formation:

$\mathrm{H}^{+}+\mathrm{HO}_{2}{ }^{-} \rightarrow \mathrm{H}_{2} \mathrm{O}_{2}$.

The hydrogen and oxygen steams are confined at the anode and cathode, respectively, because of the separation by a porous solid membrane, thereby posing no danger of burning or explosion. The anodic-produced $\mathrm{H}^{+}$and cathodic-produced $\mathrm{HO}_{2}{ }^{-}$combine with each other in the membrane to form pure
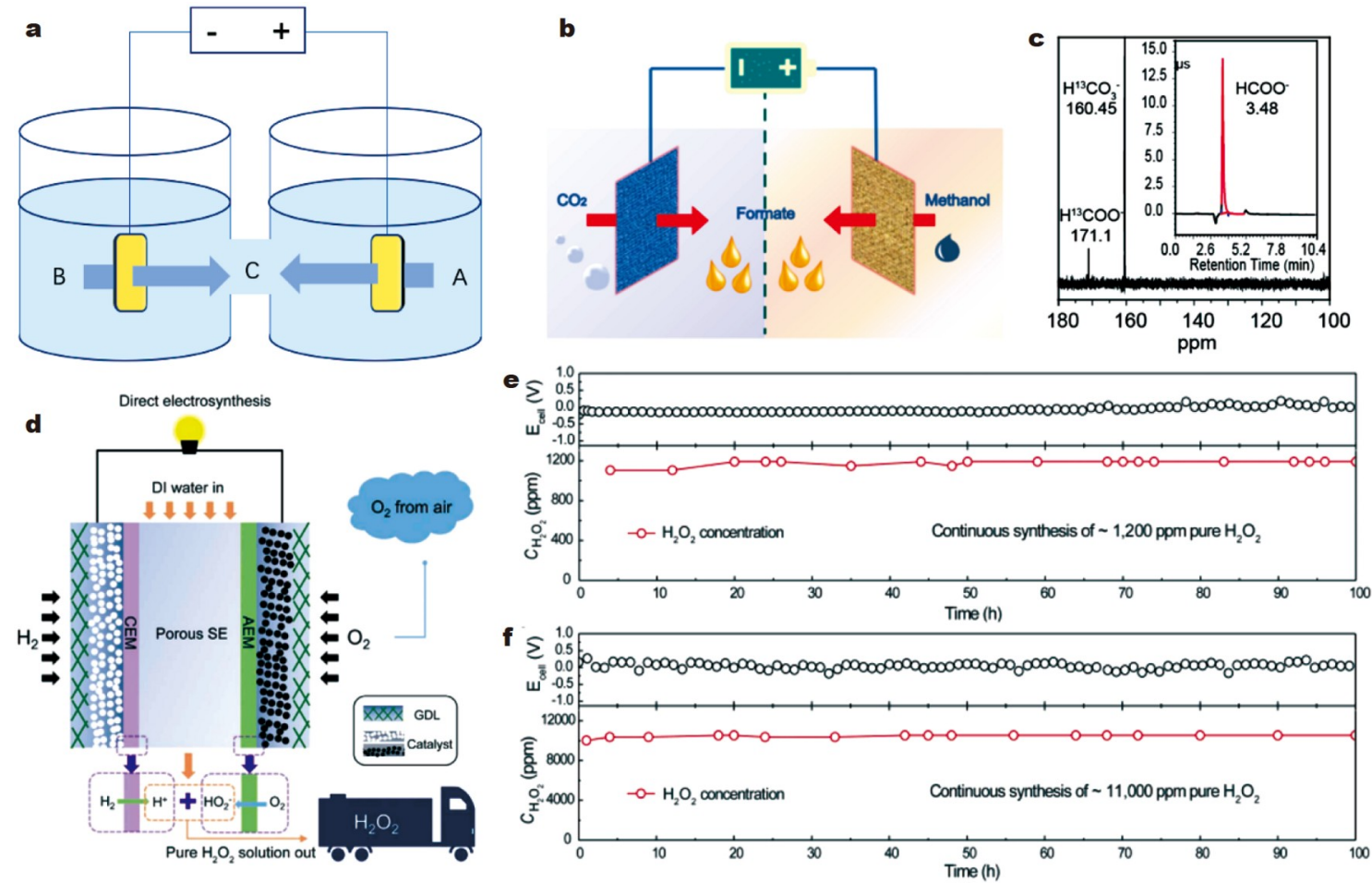

Figure 3 Schematic illustrations of (a) electrochemical conversions of two precursors at both sides into one/the same product and (b) concurrent electrocatalytic chemical conversions of anodic methanol by partial oxidation and cathodic carbon dioxide by reduction to the same product, formic acid. (c) Ion chromatographic spectrum (inset) and ${ }^{13} \mathrm{C}$ nuclear magnetic resonance $\left({ }^{13} \mathrm{C} \mathrm{NMR}\right)$ spectrum of the electrolyte after long-time electrochemical test. Reprinted from Ref. [7] with permission, Copyright 2019, Wiley-VCH Verlag GmbH \& Co. KGaA. (d) Schematic illustration of the synthesis of hydrogen peroxide by anodic hydrogen oxidation and cathodic oxygen reduction. (e, f) Stability tests for hydrogen peroxide synthesis at concentrations higher than 1000 ppm (e) and 10,000 ppm (f). Reprinted from Ref. [32] with permission, Copyright 2019, The Authors, exclusive licensee American Association for the Advancement of Science. 
aqueous hydrogen peroxide solution. A selectivity of higher than $90 \%$ for hydrogen peroxide at the current density of $200 \mathrm{~mA} \mathrm{~cm}^{-2}$ was obtained, presenting an exciting productivity of $3.4 \mathrm{mmol} \mathrm{cm}^{-2} \mathrm{~h}^{-1}$ for hydrogen peroxide. Moreover, hydrogen peroxide with varied concentrations can be obtained by tuning the rate of water flow through the solid but porous membrane because only one product, namely, hydrogen peroxide, was obtained by the co-electrolysis of hydrogen and oxygen simultaneously at both anode and cathode. Moreover, further purifications and distillations are not needed, which means cost reduction and high economic profit. This co-electrolysis strategy is believed to be extendible to other electrocatalytic systems for producing high value-added chemicals with high purity and high concentration.

In addition to the concurrent electroreactions at both sides, a successive reaction route was also proposed. Typically, the intermediate product of the added chemical precursor at one side of the electrolyzer may diffuse into another side, where it electrochemically converts into the final target product. Wang et al. [33] proposed an interesting strategy of converting $\mathrm{N}_{2}$ to $\mathrm{NO}_{3}{ }^{-}$at the anode and then $\mathrm{NO}_{3}{ }^{-}$to $\mathrm{NH}_{3}$ at the cathode. $\mathrm{N}_{2}$ from the air was electro-oxidized to $\mathrm{HNO}_{3}$ by using $\mathrm{Pt}$ foil as the model catalyst at the anode, which showed $\mathrm{NO}_{3}{ }^{-}$generation at the rate of $0.06 \mu \mathrm{mol} \mathrm{h}^{-1} \mathrm{~cm}^{-2}$ at $2.19 \mathrm{~V}$. At the cathode, $\mathrm{NO}_{3}^{-}$ could be reduced to $\mathrm{NH}_{3}$ using $\mathrm{Co}_{3} \mathrm{O}_{4}$ nanorod arrays supported on $\mathrm{Ti}$ mesh, which showed a selectivity of $33.6 \%$ for $\mathrm{NH}_{3}$ at $-0.65 \mathrm{~V}$. Under the present condition, the $\mathrm{NO}_{3}{ }^{-}$amount obtained at the anode is still too low to be used at the cathode, but in the future, anodic $\mathrm{NO}_{3}{ }^{-}$may serve as the reactant at the cathode for ammonia synthesis once highly active catalysts can be found. In this regard, far more active electrocatalysts are critically important for the development of these successive coelectrolysis systems.

\section{DOUBLE/MULTIPLE ELECTROCHEMICAL CONVERSIONS AT ONE SIDE}

Among the above three types of co-electrolysis, chemical precursors are reduced or oxidized at the cathode and anode concurrently, but only one reaction dominates at each electrode. If more than one chemical is added at the same side of an electrolyzer, then the interactions among them may benefit the formation of multiple value-added products (Fig. 4a).

For example, although various efficient electrocatalysts have been developed, hydrogen evolution is still unavoidable in the process of $\mathrm{CO}_{2}$ electroreduction due to the relatively low potential needed for HER in an aqueous solution. Moreover, CO is easy to obtain in $\mathrm{CO}_{2}$ reduction because the conversion is a two-electron process. The question now is whether coupled coelectrolysis of $\mathrm{H}_{2} \mathrm{O}$ and $\mathrm{CO}_{2}$ for the production of syngas, $\mathrm{H}_{2}+$ $\mathrm{CO}$ mixture, can be obtained concurrently. Syngas is an important feedstock or intermediate in various chemical engineering processes, such as the syntheses of fuels, fertilizers, plastics, and solvents, generally from non-renewable fossil fuels that entail great energy consumption. Therefore, the competitive relationship between $\mathrm{HER}$ and $\mathrm{CO}_{2} \mathrm{RR}$ might turn into a synergetic relationship in the coupled co-electrolysis of earthabundant $\mathrm{H}_{2} \mathrm{O}$ and $\mathrm{CO}_{2}$. Moreover, the ratio of $\mathrm{H}_{2} / \mathrm{CO}$, which is a key factor in performing different synthetic reactions, can be easily tuned by regulating the electrocatalyst and electrocatalytic conditions, such as the potential and electrolyte. For example, Meng et al. [34] demonstrated the synthesis of lamellar organic- inorganic CdS-diethylenetriamine hybrids with adjustable $\mathrm{Zn}$ substitution, which was named $\mathrm{Zn}_{x} \mathrm{CdS}_{1-x}$-Amine (Fig. $4 \mathrm{~b}$ ). The organic diethylenetriamine benefits the adsorption and activation of $\mathrm{CO}_{2}$, while the $\mathrm{Zn}$ substitution is in favor of the HER. When serving as the electrocatalyst for co-electrolysis of $\mathrm{CO}_{2}$ and $\mathrm{H}_{2} \mathrm{O}, \mathrm{Zn}_{x} \mathrm{CdS}_{1-x}$-Amine catalyzed the syngas production with tunable composition and a high activity. $\mathrm{CO}_{2} \mathrm{RR}$ and HER are both reductive reactions and occur at the cathode, which is why the anodic reaction in coupling with the cathodic co-electrolysis of $\mathrm{CO}_{2}$ and $\mathrm{H}_{2} \mathrm{O}$ is still a kinetically slow OER process in most reports. The authors introduced kinetically fast dehydrogenation of tetrahydroisoquinoline as a substitute for OER. When the co-electrolysis of tetrahydroisoquinoline oxidation at the anode and $\mathrm{CO}_{2} / \mathrm{H}_{2} \mathrm{O}$ reduction at the cathode were paired in a two-electrode system, the cell voltage was significantly reduced by $220 \mathrm{mV}$ at the current density of $20 \mathrm{~mA} \mathrm{~cm}^{-2}$.

Ross et al. [36] tuned the $\mathrm{Cu}$ enrichment on the Au surface to change the $\mathrm{H}_{2} / \mathrm{CO}$ ratio of the produced syngas. By virtue of insitu surface-enhanced Raman spectroscopy and density functional theory (DFT) calculations, the CO binding strength on the catalysts is critically important in tuning the competing relationship in the synthesis of individual $\mathrm{CO}$ or $\mathrm{H}_{2}$. Therefore, syngas of widely varied composition can be synthesized from the co-electrolysis of $\mathrm{CO}_{2}$ and $\mathrm{H}_{2} \mathrm{O}$ with an enhanced production rate. Liu et al. [37] found that the current densities and Faraday efficiency of $\mathrm{Pd} / \mathrm{NbN}$ are much higher than those of $\mathrm{Pd} / \mathrm{VN}$ and commercial $\mathrm{Pd} / \mathrm{C}$, which is ascribed to the formation of $\mathrm{PdH}$ under $\mathrm{CO}_{2}$ reduction reaction conditions and the $* \mathrm{HOCO}$ stabilization and $\mathrm{CO}$ binding weakening on $\mathrm{NbN}$.

Another example, both $\mathrm{CO}_{2}$ fixation and $\mathrm{N}_{2}$ reduction to $\mathrm{NH}_{3}$ are critically important reactions but suffer from slow kinetics and poor Faraday efficiency. Chen et al. [35] reported the cathodic co-electrolysis of $\mathrm{CO}_{2}$ and $\mathrm{N}_{2}$ for the green synthesis of valuable urea at ambient temperature and pressure (Fig. 4c-e). Generally, urea is synthesized by the reaction between $\mathrm{NH}_{3}$ and $\mathrm{CO}_{2}\left(\mathrm{NH}_{3}+\mathrm{CO}_{2} \rightarrow \mathrm{CO}\left(\mathrm{NH}_{2}\right)_{2}\right)$, and $\mathrm{NH}_{3}$ is obtained from the Haber-Bosch process $\left(\mathrm{N}_{2}+\mathrm{H}_{2} \rightarrow \mathrm{NH}_{3}\right)$. However, harsh conditions, such as high temperature and high pressure under the assistance of catalysts, are necessary for both reactions. Recently, $\mathrm{PdCu} / \mathrm{TiO}_{2}$ was used as the electrocatalyst for the co-electrolysis of $\mathrm{CO}_{2}$ and $\mathrm{N}_{2}$. Impressively, the catalyst showed much enhanced chemisorption toward $\mathrm{CO}_{2}$ and $\mathrm{N}_{2}$ after loading $\mathrm{PdCu}$ alloy, and competitive chemisorption between $\mathrm{N}_{2}$ and $\mathrm{CO}_{2}$ was negligible, which is critically important for the efficient synthesis of urea. DFT calculation indicates that the presence of activated nitrogen is in favor of the $\mathrm{CO}_{2}$ conversion to $\mathrm{CO}$ at adjacent catalytic active sites. As a result, $3.36 \mathrm{mmol} \mathrm{g}^{-1} \mathrm{~h}^{-1}$ urea can be obtained at $-0.4 \mathrm{~V} v s$. RHE with a Faraday efficiency of $8.92 \%$. This work integrates the electrolysis of $\mathrm{CO}_{2}$ and $\mathrm{N}_{2}$ at the same cathode, both of which have difficulty taking place individually, and demonstrates the efficient formation of the same product urea at the cathode by coupled co-electrolysis of $\mathrm{CO}_{2}$ and $\mathrm{N}_{2}$.

\section{CONCLUSIONS AND OUTLOOK}

Efficient electrolysis using renewable electric power for high value-added chemical production is of great importance to the sustainable development of our society. The bottlenecks typically encountered in attempts to obtain single high-value products have inspired scientists to explore novel electrolytic strategies of synthesizing double/multiple products in one electrolytic system while diminishing the energy consumption. To this end, co- 

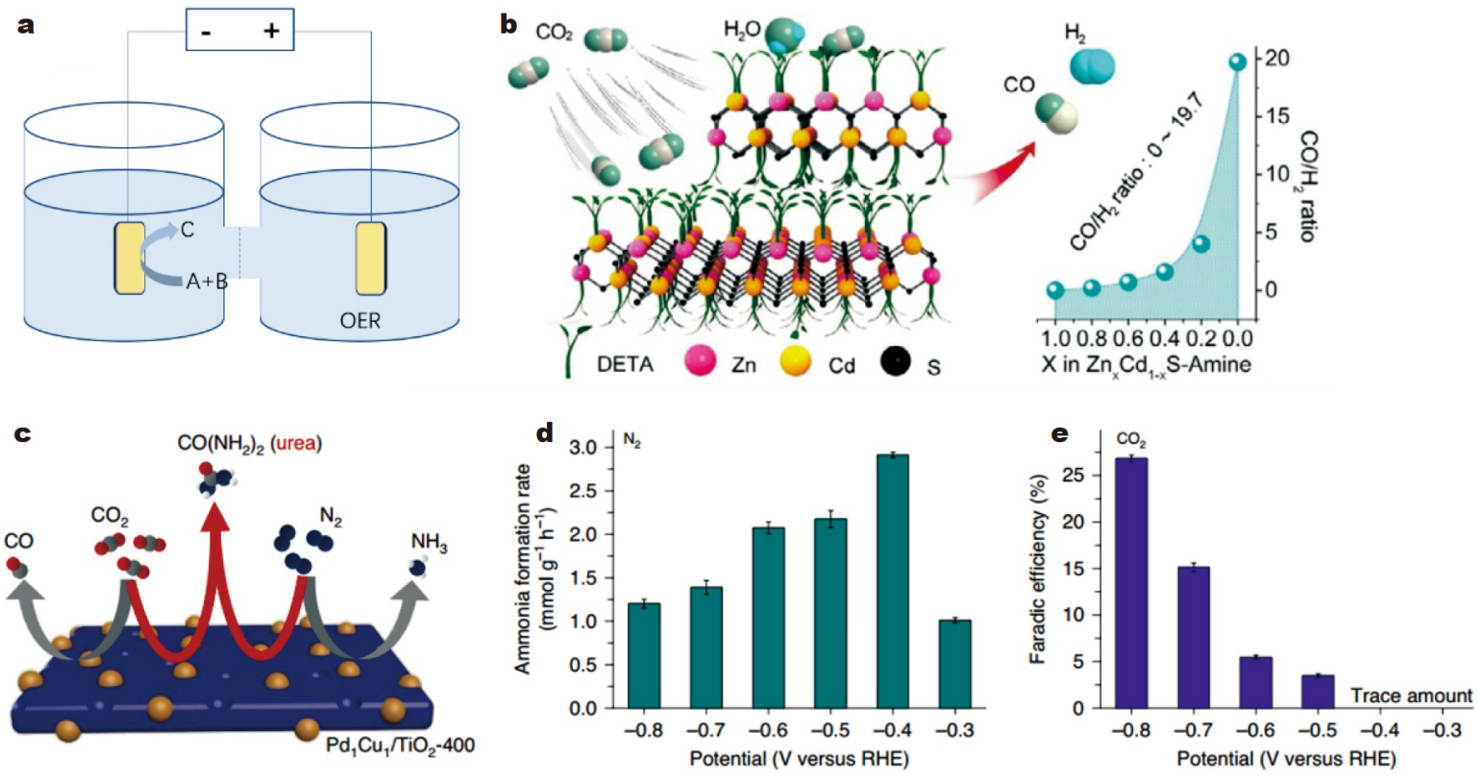

Figure 4 Schematic illustrations of (a) double/multiple electrochemical conversions at one side and (b) co-electrolysis of carbon dioxide and water for the production of syngas with tunable $\mathrm{CO} / \mathrm{H}_{2}$ ratios using $\mathrm{Zn}_{x} \mathrm{Cd}_{1-x} \mathrm{~S}$-Amine as the electrocatalyst. Reprinted from Ref. [34] with permission, Copyright 2019, Wiley-VCH Verlag GmbH \& Co. KGaA. (c) Schematic illustration of the co-electrolysis of $\mathrm{N}_{2}$ and $\mathrm{CO}_{2}$ for the synthesis of urea; (d) ammonia formation rate with $\mathrm{N}_{2}$ as the feeding gas, and (e) Faraday efficiency of urea with $\mathrm{CO}_{2}$ as the feeding gas. Reprinted from Ref. [35] with permission, Copyright 2020, The Author(s), under exclusive licence to Springer Nature Limited.

electrolysis of more than one chemical precursor has been considered one of the major promising approaches. In this tutorial review, recent progress in this field is classified into four categories according to the different configurations of the electrolytic system and/or different types of electrolysis reactions. First, agent sacrificing at one electrode promoting the electrochemical precursor conversion at the other: to displace the kinetically sluggish anodic OER, kinetically favorable sacrificial agents could be introduced into the electrolyte for preferred oxidation, substituting for OER and at a much lowered potential in comparison to OER. Thus, a high-value cathodic product can be obtained at reduced power consumption. Second, parallel electrochemical precursor conversions simultaneously at both sides: two chemicals are reduced and oxidized respectively and simultaneously at the cathode and the anode to obtain the corresponding high value-added products at both sides. Third, electrochemical conversions of two precursors at both sides into the same product: two chemicals are reduced and oxidized respectively at the cathode and anode, but only one high valueadded product will be generated by the anodic and cathodic reactions concurrently or successively. Finally, double/multiple electrochemical conversions at one side: two or more chemicals can be produced from the corresponding precursors introduced at one electrode.

Typical and most recent progress in the co-electrolysis system was reviewed according to the above classifications. However, the development of co-electrolysis systems for high value-added products is still in its early stages, especially when compared with traditional systems of synthesizing single-target products from one chemical precursor. The following issues need to be paid attention to in further research on co-electrolysis.

(1) Novel co-electrolysis configuration design

Although increasing efforts have been made to develop coelectrolysis systems and significant progress has been achieved, more novel co-electrolysis configurations and corresponding systems should be designed for the syntheses of high valueadded products at lower costs. First, a favorable combination between two or more strategies discussed above may be a simple and straightforward approach to design novel co-electrolysis configurations. For example, the counter electrode (anode) reaction to the double/multiple electrochemical conversions at one side (cathode) strategy is currently the kinetically slow OER. This OER can be altered with a kinetically favorable reaction to lower the total energy input by integrating with the strategy of an agent sacrificing at one electrode and promoting electrochemical precursor conversion at the other. In addition, no report exists on the co-oxidation reactions at the anode to synthesize high value-added chemicals. Moreover, factors such as the electrolyte, membrane, and electrolyzer configuration should be investigated and optimized for efficient co-electrolysis. In addition to co-electrolysis, other energy resources, such as solar, may be used in the simultaneous conversion of chemical precursors.

\section{(2) Mechanism investigation}

Although intensive research has been conducted on the mechanisms of traditional electrolysis systems, such as HER, OER, $\mathrm{CO}_{2} \mathrm{R}$, and NRR, the mechanism of co-electrolysis systems is different from these and no doubt more complicated. In the co-electrolysis systems, more than one kind of chemical precursors are added, and one or more kinds of products can be obtained, which are different from typical $\mathrm{HER} / \mathrm{CO}_{2} \mathrm{R} / \mathrm{NRR}$ reactions. Therefore, the interactions between these species should be brought to the forefront to target value-added chemicals at lowered power consumption. In addition to the kinetics of each reaction, the interaction among the chemical precursors, reaction intermediates, and electrocatalysts plays an important role in affecting the reaction pathways and kinetics, and even determining the overall revenue. In-situ or operando 
observation technologies, such as in-situ transmission electron microscopy (TEM), Fourier transformed infrared spectroscopy (FT-IR), and Raman spectroscopy, are necessary and helpful in investigating the mechanism of co-electrolysis systems. DFT calculations are also important tools to explain, understand, and predict the reaction mechanisms and the interactions between chemicals, intermediates, and electrocatalysts. Moreover, although insights on the mechanism of co-electrolysis have rarely been reported, the oxidation mechanism of biomass [38] or nucleophile [39] can shed light on its exploration.

(3) Efficient electrocatalyst design

Although the optimized design of co-electrolysis configuration is of great importance in producing high value-added chemicals at a relatively lowered energy input, the electrocatalysts are of equal importance. No general electrocatalysts are available for all these systems because of the wide variety of co-electrolysis systems and reactions. Therefore, specific electrocatalysts should be identified and developed for designated co-electrolytic reaction systems. The following items should be considered in investigating electrocatalysts. First, an effective electrocatalyst should be specifically efficient for catalyzing desired reactions rather than competitive side reactions producing low-value substances. For example, anodic electrocatalysts should be designed to favor the chemical production of enhanced values rather than OER. Second, the electrocatalysts should be optimized for enhanced active site density and electrocatalytic activity on the basis of the mechanism investigation. Third, electrocatalysts with high and stable electrochemical performances should be cost-effective, containing no noble elements that favor potential practical applications.

(4) Product purification

More than one product can be generated in the co-electrolysis system, which is why the mixing of these products should be prevented, or the desired product can be easily extracted from the mixture. Some liquid products will inevitably dissolve in the aqueous electrolyte, which should be purified or concentrated without difficulties for further applications. Furthermore, as effective alternatives for conventional aqueous electrolytes, solid or quasi-solid polymeric electrolytes are therefore highly attractive for producing high-purity and high-concentration target chemicals, as illustrated in the electrosynthesis of hydrogen peroxide and formic acid [32,40]. Nevertheless, more efforts are necessary to develop novel and/or optimized co-electrolysis systems to fabricate high-purity and/or -concentration products easily and economically.

Received 15 August 2021; accepted 23 September 2021; published online 2 November 2021

1 Zhang JY, He T, Wang M, et al. Energy-saving hydrogen production coupling urea oxidation over a bifunctional nickel-molybdenum nanotube array. Nano Energy, 2019, 60: 894-902

2 You B, Sun Y. Innovative strategies for electrocatalytic water splitting. Acc Chem Res, 2018, 51: 1571-1580

3 Zhao X, Du L, You B, et al. Integrated design for electrocatalytic carbon dioxide reduction. Catal Sci Technol, 2020, 10: 2711-2720

$4 \mathrm{Li} \mathrm{Y}$, Wei X, Chen L, et al. Electrocatalytic hydrogen production trilogy. Angew Chem Int Ed, 2021, 60: 19550-19571

5 Verma S, Lu S, Kenis PJA. Co-electrolysis of $\mathrm{CO}_{2}$ and glycerol as a pathway to carbon chemicals with improved technoeconomics due to low electricity consumption. Nat Energy, 2019, 4: 466-474

6 Chen L, Shi J. Chemical-assisted hydrogen electrocatalytic evolution reaction (CAHER). J Mater Chem A, 2018, 6: 13538-13548
7 Wei X, Li Y, Chen L, et al. Formic acid electro-synthesis by concurrent cathodic $\mathrm{CO}_{2}$ reduction and anodic $\mathrm{CH}_{3} \mathrm{OH}$ oxidation. Angew Chem Int Ed, 2021, 60: 3148-3155

8 Huang C, Huang Y, Liu C, et al. Integrating hydrogen production with aqueous selective semi-dehydrogenation of tetrahydroisoquinolines over a $\mathrm{Ni}_{2} \mathrm{P}$ bifunctional electrode. Angew Chem Int Ed, 2019, 58: 12014-12017

9 You B, Liu X, Jiang N, et al. A general strategy for decoupled hydrogen production from water splitting by integrating oxidative biomass valorization. J Am Chem Soc, 2016, 138: 13639-13646

10 Tang C, Zhang R, Lu W, et al. Energy-saving electrolytic hydrogen generation: $\mathrm{Ni}_{2} \mathrm{P}$ nanoarray as a high-performance non-noble-metal electrocatalyst. Angew Chem Int Ed, 2017, 56: 842-846

11 Li Y, Zhang J, Liu Y, et al. Partially exposed $\mathrm{RuP}_{2}$ surface in hybrid structure endows its bifunctionality for hydrazine oxidation and hydrogen evolution catalysis. Sci Adv, 2020, 6: eabb4197

12 Zhang JY, Wang H, Tian Y, et al. Anodic hydrazine oxidation assists energy-efficient hydrogen evolution over a bifunctional cobalt perselenide nanosheet electrode. Angew Chem Int Ed, 2018, 57: 7649-7653

13 Sun F, Qin J, Wang Z, et al. Energy-saving hydrogen production by chlorine-free hybrid seawater splitting coupling hydrazine degradation. Nat Commun, 2021, 12: 4182

$14 \mathrm{Li}$ Y, Wei X, Chen L, et al. Nickel-molybdenum nitride nanoplate electrocatalysts for concurrent electrolytic hydrogen and formate productions. Nat Commun, 2019, 10: 5335

15 Liu WJ, Xu Z, Zhao D, et al. Efficient electrochemical production of glucaric acid and $\mathrm{H}_{2}$ via glucose electrolysis. Nat Commun, 2020, 11: 265

16 Zhao B, Liu J, Xu C, et al. Hollow NiSe nanocrystals heterogenized with carbon nanotubes for efficient electrocatalytic methanol upgrading to boost hydrogen Co-production. Adv Funct Mater, 2020, 31: 2008812

17 Chen YX, Lavacchi A, Miller HA, et al. Nanotechnology makes biomass electrolysis more energy efficient than water electrolysis. Nat Commun, 2014, 5: 4036

18 Huang Y, Chong X, Liu C, et al. Boosting hydrogen production by anodic oxidation of primary amines over a NiSe nanorod electrode. Angew Chem Int Ed, 2018, 57: 13163-13166

19 Huang $\mathrm{H}, \mathrm{Yu} \mathrm{C}, \mathrm{Han} \mathrm{X}$, et al. $\mathrm{Ni}$, Co hydroxide triggers electrocatalytic production of high-purity benzoic acid over $400 \mathrm{~mA} \mathrm{~cm}{ }^{-2}$. Energy Environ Sci, 2020, 13: 4990-4999

20 Si D, Xiong B, Chen L, et al. Highly selective and efficient electrocatalytic synthesis of glycolic acid in coupling with hydrogen evolution. Chem Catal, 2021, 1: 941-955

21 Li T, Cao Y, He J, et al. Electrolytic $\mathrm{CO}_{2}$ reduction in tandem with oxidative organic chemistry. ACS Cent Sci, 2017, 3: 778-783

22 Wang Y, Gonell S, Mathiyazhagan UR, et al. Simultaneous electrosynthesis of syngas and an aldehyde from $\mathrm{CO}_{2}$ and an alcohol by molecular electrocatalysis. ACS Appl Energy Mater, 2019, 2: 97-101

23 Bajada MA, Roy S, Warnan J, et al. A precious-metal-free hybrid electrolyzer for alcohol oxidation coupled to $\mathrm{CO}_{2}$-to-syngas conversion. Angew Chem Int Ed, 2020, 59: 15633-15641

24 Zhou H, Li Z, Xu SM, et al. Selectively upgrading lignin derivatives to carboxylates through electrochemical oxidative $\mathrm{C}(\mathrm{OH})-\mathrm{C}$ bond cleavage by a Mn-doped cobalt oxyhydroxide catalyst. Angew Chem Int Ed, 2021, 60: 8976-8982

25 Chong X, Liu C, Wang C, et al. Integrating hydrogen production and transfer hydrogenation with selenite promoted electrooxidation of $\alpha$ nitrotoluenes to $E$-nitroethenes. Angew Chem Int Ed, 2021, 60: 2201022016

26 Zhang P, Sheng X, Chen X, et al. Paired electrocatalytic oxygenation and hydrogenation of organic substrates with water as the oxygen and hydrogen source. Angew Chem Int Ed, 2019, 58: 9155-9159

27 Luo J, Wang M, Chen L, et al. Efficient benzaldehyde photosynthesis coupling photocatalytic hydrogen evolution. J Energy Chem, 2022, 66: $52-60$

28 Chai Z, Zeng TT, Li Q, et al. Efficient visible light-driven splitting of alcohols into hydrogen and corresponding carbonyl compounds over a Ni-modified CdS photocatalyst. J Am Chem Soc, 2016, 138: 1012810131 
29 Wu B, Zhang L, Jiang B, et al. Ultrathin porous carbon nitride bundles with an adjustable energy band structure toward simultaneous solar photocatalytic water splitting and selective phenylcarbinol oxidation. Angew Chem Int Ed, 2021, 60: 4815-4822

30 Shang W, Li Y, Huang $\mathrm{H}$, et al. Synergistic redox reaction for valueadded organic transformation via dual-functional photocatalytic systems. ACS Catal, 2021, 11: 4613-4632

31 Guo $\mathrm{C}, \mathrm{He} \mathrm{P}$, Cui $\mathrm{R}$, et al. Electrochemical $\mathrm{CO}_{2}$ reduction using electrons generated from photoelectrocatalytic phenol oxidation. Adv Energy Mater, 2019, 9: 1900364

32 Xia C, Xia Y, Zhu P, et al. Direct electrosynthesis of pure aqueous $\mathrm{H}_{2} \mathrm{O}_{2}$ solutions up to $20 \%$ by weight using a solid electrolyte. Science, 2019, 366: 226-231

33 Wang $\mathrm{Y}, \mathrm{Yu} \mathrm{Y}$, Jia R, et al. Electrochemical synthesis of nitric acid from air and ammonia through waste utilization. Natl Sci Rev, 2019, 6: 730738

34 Meng N, Liu C, Liu Y, et al. Efficient electrosynthesis of syngas with tunable $\mathrm{CO} / \mathrm{H}_{2}$ ratios over $\mathrm{Zn}_{x} \mathrm{Cd}_{1-x} \mathrm{~S}$-amine inorganic-organic hybrids. Angew Chem Int Ed, 2019, 58: 18908-18912

35 Chen $\mathrm{C}$, Zhu X, Wen $\mathrm{X}$, et al. Coupling $\mathrm{N}_{2}$ and $\mathrm{CO}_{2}$ in $\mathrm{H}_{2} \mathrm{O}$ to synthesize urea under ambient conditions. Nat Chem, 2020, 12: 717-724

36 Ross MB, Dinh CT, Li Y, et al. Tunable Cu enrichment enables designer syngas electrosynthesis from $\mathrm{CO}_{2}$. J Am Chem Soc, 2017, 139: 93599363

37 Liu Y, Tian D, Biswas AN, et al. Transition metal nitrides as promising catalyst supports for tuning $\mathrm{CO} / \mathrm{H}_{2}$ syngas production from electrochemical $\mathrm{CO}_{2}$ reduction. Angew Chem Int Ed, 2020, 59: 11345-11348

38 Deng $\mathrm{X}, \mathrm{Xu}$ GY, Zhang YJ, et al. Understanding the roles of electrogenerated $\mathrm{Co}^{3+}$ and $\mathrm{Co}^{4+}$ in selectivity-tuned 5-hydroxymethylfurfural oxidation. Angew Chem Int Ed, 2021, 60: 20535-20542

39 Chen W, Xie C, Wang Y, et al. Activity origins and design principles of nickel-based catalysts for nucleophile electrooxidation. Chem, 2020, 6: 2974-2993

40 Fan L, Xia C, Zhu P, et al. Electrochemical $\mathrm{CO}_{2}$ reduction to highconcentration pure formic acid solutions in an all-solid-state reactor. Nat Commun, 2020, 11: 3633

Acknowledgements This work was supported by the Natural Science Foundation of Shanghai (21ZR1418700), China Postdoctoral Science Foundation funded project (2020T130193), and the Fundamental Research Funds for the Central Universities.

Author contributions Chen L wrote and revised the manuscript; Shi J revised and polished the manuscript. Both authors contributed to the general discussion.

Conflict of interest The authors declare that they have no conflict of interest.

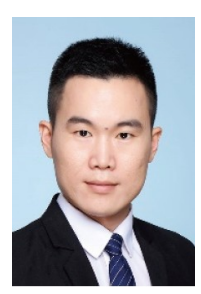

Lisong Chen received his $\mathrm{PhD}$ degree under the supervision of Prof. Jianlin Shi from Shanghai Institute of Ceramics, Chinese Academy of Sciences (SICCAS) in 2016. He is now an associate professor at East China Normal University. His research focuses on electrocatalysts for renewable energy.

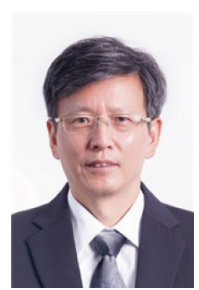

Jianlin Shi received his $\mathrm{PhD}$ degree from SICCAS. He is now a professor there and an academician of the Chinese Academy of Sciences. His research areas include the synthesis of mesoporous-based nanomaterials and their catalytic and biomedical applications, and more recently, electrocatalysis.

\section{面向高附加值化学品制备的共电解催化}

\author{
陈立松 $1^{*}$, 施剑林 $2^{*}$
}

摘要 当前常见的电催化反应大多以制备某一种化学品为目标, 如水 分解析氢、二氧化碳还原制备碳基化学品、氮气还原制氨等, 然而这 些电催化反应均面临着严重的竞争反应且需要克服对电极反应较大的 能垒. 在同一电解池中共电解两种或多种化学原料有望减弱竞争反应 并降低对电极反应能垒, 从而达到在较低能耗下制备高附加值化学品 的目的. 虽然共电解催化体系已经有了一定的发展, 但目前尚未见到 该主题相关的综述. 本综述将共电解催化体系分为: (1) 牺牲剂促进的 电化学转化; (2) 两电极上同时分别进行的电化学转化; (3) 两电极共同 作用将两种原料转化为一种/类产物; (4) 在一个电极上将多种原料转 化为一种产物. 最后提出共电解催化体系未来发展面临的诸多机遇和 挑战. 